\title{
Email Usage in South Pacific Distance Education
}

\author{
Jonathan Frank \\ Suffolk University, USA \\ Janet Toland \\ Victoria University of Wellington, New Zealand \\ Karen D. Schenk \\ K.D. Schenk and Associates Consulting, USA
}

\section{INTRODUCTION}

The impact of cultural diversity on group interactions through technology is an active research area. Current research has found that a student's culture appears to influence online interactions with teachers and other students (Freedman \& Liu, 1996). Students from Asian and Western cultures have different Web-based learning styles (Liang \& McQueen, 1999), and Scandinavian students demonstrate a more restrained online presence compared to their more expressive American counterparts (Bannon, 1995). Differences were also found across cultures in online compared to face-to-face discussions (Warschauer, 1996). Student engagement, discourse, and interaction are valued highly in "western" universities. With growing internationalization of western campuses, increasing use of educational technology both on and off campus, and rising distance learning enrollments, intercultural frictions are bound to increase.

This research adds to the body of knowledge by evaluating e-mail effectiveness as a communication medium in facilitating meaningful class participation in two distance education institutions. This work investigates online student interaction in the South Pacific region. The scattered geography of the South Pacific has produced immense variations in culture among a relatively low population base. For example, in the tiny island group of Vanuatu with a population of less than 200,000, over 110 different languages are spoken (Myers \& Tan, 2002). This makes the South Pacific an ideal laboratory in which to explore the impact of cultural differences on online learning, as the region contains a broad representation of the cultural characteristics found throughout the world.

Subjects were drawn from business information systems and computer information technology classes at the University of the South Pacific and Central Queensland University. Three research questions were addressed:

- Does cultural background affect the extent to which distance education students use e-mail to commu- nicate with educators and other students for academic and social reasons?

- Does cultural background affect the academic content of e-mail messages from distance education students?

- Does cultural background influence distance education students' preference to ask questions or provide answers using e-mail instead of face-toface communication?

\section{BACKGROUND}

There have been a number of papers that have examined the impact of cultural diversity and group interaction in computer-mediated communication environments (Jarvenpaa \& Leidner, 1998). Hofstede's (1991) well-known model categorizes different cultures according to five pairs of dimensions (Figure 1)

Although not exhaustive, Hofstede's model has been widely used, and it provides a useful starting point for exploring the influence of cultural backgrounds (Holden, 2002; Myers \& Tan, 2002). For this research the focus was on the dimensions of individualism versus collectivism, and high power distance versus low power distance. These two dimensions were considered to have the most impact on learning style, the individualism/collectivism dimension will affect the way students interact with their peers, and the power distance dimension will influence the way they interact with their professor.

Hofstede's work indicated that there was a strong correlation between a country's national wealth and the degree of individualism in its culture. Richer countries tend to have an individualistic style, whereas poorer countries are more collectivist. As a poorer country becomes wealthier, it tends to move towards an individualistic pattern. Additionally, people from a rural background tend to be more collectivist than those from an urban background. Countries which fall into the low power distance, individualist category are Australia, New 
Figure 1. Hofstede's model of cultural differences

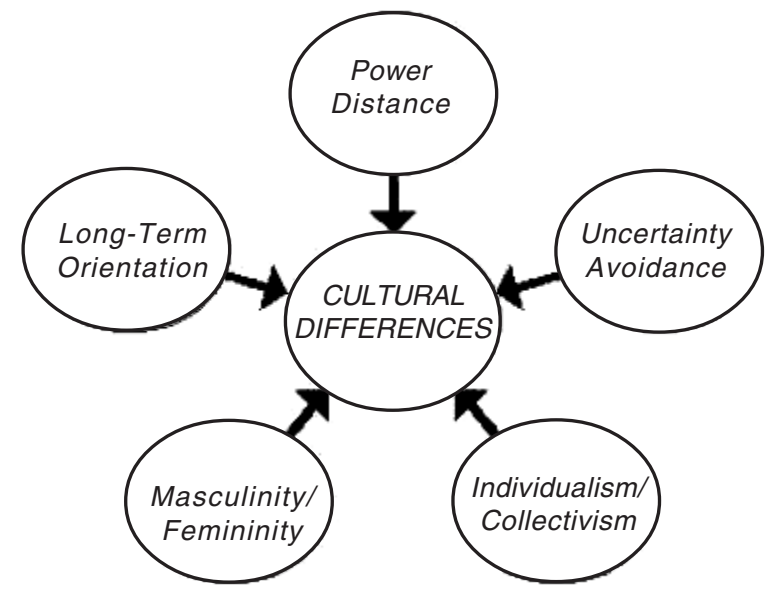

Zealand, North America, England, and Scandinavia; countries in Asia, India, and South America would be considered high power distance and collectivist (Hofstede, 1991).

If a country is collectivist, it is also likely to exhibit characteristics of a high power distance country, where the views of senior people tend not to be questioned. Pacific Island people are in the high power distance category with their system of chiefs and their tradition of not questioning the chief's decision. South Pacific society is also collectivist with the custom of "Kere Kere" or not being able to refuse a favor that is asked of you by a member of your own in-group.
There have been a number of recent publications reviewing aspects of the development of IT in the South Pacific (Davis, McMaster \& Nowak, 2002; Olutimayin, 2002; Purcell \& Toland, 2004), however no research has yet been published that maps Hofstede's model on the many South Pacific cultures. Lynch, Szorengi, and Lodhia (2002) have explored Hofstede's framework with respect to Fiji, hypothesizing where the indigenous Fijian population and the Indo Fijian population would fit into the framework, however they are still in the process of collecting empirical evidence to validate their theories. This research forms a useful starting point to locate South Pacific cultures on the dimensions of individualism, collectivism, and power distance.

Most research on the effect of cultural differences has focused on traditional face-to-face teaching, rather than distance education. The literature has often cited difficulties in motivating students from collectivist (as opposed to individualistic) cultures to "speak up" in a face-to-face learning situation. Students from a collectivist culture prefer to listen, reflect, and discuss material with their peers, before preparing a written response. In common with many other collectivist cultures, it would be considered undesirable for students to speak up in class, as communication is mostly teacher centered. In Fiji, lecturers have widely commented on the "quietness" of their students (Handel, 1998). Additionally, in some pacific cultural norms, student silence is seen as a sign of respect for teachers (Matthewson et al., 1998).

More research is needed to understand fully the cultural contexts in which distance education programs are situated and how distance students process materials, especially in a second language (Guy, 1991). One study

Figure 2. Container model of knowledge transfer

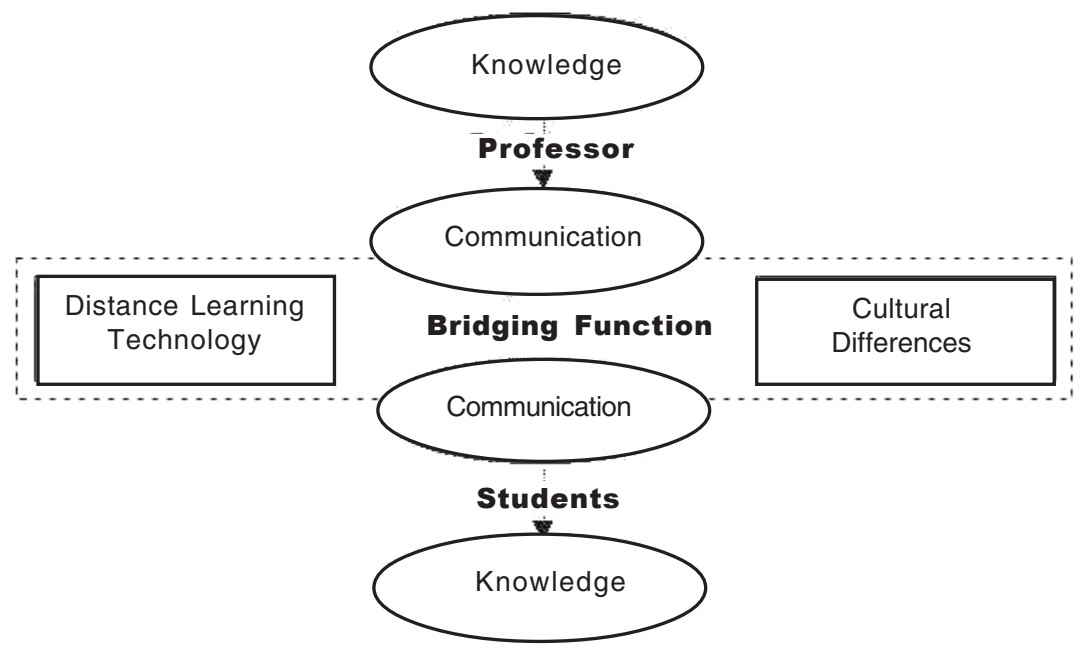


concluded that students from collectivist cultures would be less receptive to distance education than students from individualistic cultures. Cultural differences also affect the way students interact with different types of messages (Anakwe, 1999). It has been shown that students from individualistic cultures are more willing to respond to ambiguous messages, which may result in a different approach to e-mail (Gudykunst, 1997).

\section{THE SOUTH PACIFIC STUDY}

The two distance education institutions studied have different approaches to education. In the University of the South Pacific (USP), knowledge transfer tends to occur in a one-directional mode from professor to student. This familiar model is often called the container or transfer model of knowledge transfer, or migratory knowledge (Badaracco, 1991). USP's distance education model reflects the traditional correspondence course model, in that learning materials are packaged for students, and little interaction is anticipated between student and teacher. Figure 2 proposes an adaptation of the container model, incorporating a bridging function (Jin et al., 1998) as well as components to reflect the effect of distance learning technology and cultural factors on knowledge transfer.

In contrast, Central Queensland University (CQU) distance education pedagogy is extraordinarily dependent on e-mail interaction between students and professors. Fifty percent of students' grades are based on group exercises. Groups consist of 5-10 students from 12 coun- tries. Students are assigned to groups by the course coordinator to maximize in-group diversity. Students are required to post within group and between group evaluations to a threaded discussion forum each week. Students are encouraged to learn from each other, as well as their professor (Romm, 2001; Jones, 1999).

The social construction model of learning and knowledge transfer (Figure 3) fits well with the CQU approach to learning. This model represents knowledge as one part of a process. It considers knowledge, cognition, action, and communication as inseparable.

"The term enactment captures this interrelationship among the different aspects of knowing, acting, communicating, and perceiving. Knowledge takes on meaning as the entity interacts with its environment through communicating with other entities, acting (and thereby changing the environment) and interpreting cues arising from these interactions." Weick (1979)

\section{FINDINGS}

To assess the impact of these two approaches to distance education on students from different cultures, two studies were conducted in parallel. The University of South Pacific study examined how distance education students from different cultural backgrounds used e-mail to communicate with other students and teachers. Four hundred USP students located at different regional centers were surveyed about their e-mail usage. In the Central Queensland University study, postings to threaded dis-

Figure 3. Social construction model of knowledge transfer

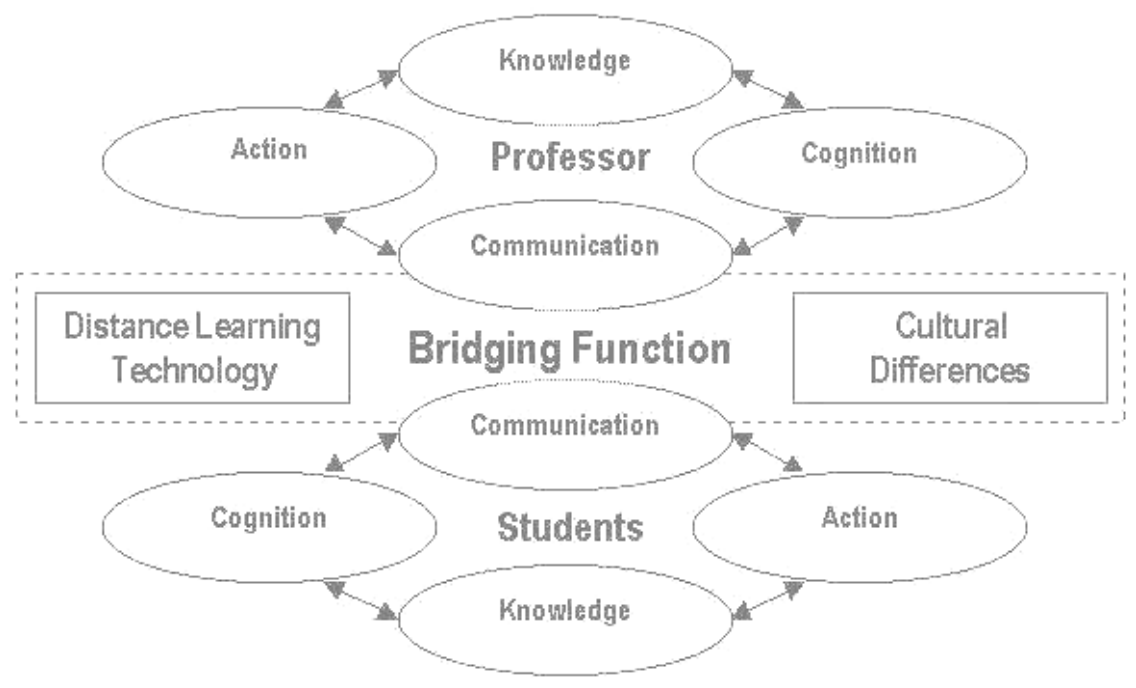


cussion groups by 867 distance education students based in Fiji and Australia were analyzed. For a detailed discussion of research methodology and findings, see Frank, Toland, and Schenk (2004).

Study findings suggested differences in usage of email by students from individualistic and collectivist cultures both in terms of the quantity of messages sent, and in the nature of those messages. Australian students (individualist - low power distance culture) send significantly more posts to their discussion board than do Fijian students (collectivist-high power distance culture). Australian students appear more ready to respond to questions than Fijian students do. Fijian students volunteer fewer answers to the threaded discussion group. One explanation might be associated with fear of "losing face" among their peer group. Another possibility might be Fijian students view participation on the list as not directly affecting their grade, and therefore see no reason to volunteer answers.

An analysis of Fijian messages confirmed that a large percentage of messages were social in nature; students seem to use the lists more for forming groups than Australian students. Further investigation of questions asked by Fijian students indicated a need for reduction in ambiguity about assignment specifications.

\section{CONCLUSION}

The South Pacific region, isolated, vast, and culturally diverse, was selected as an appropriate research environment in which to study the effect of cultural differences and educational technology on distance education. The research context was two competing distance education institutions in Fiji: the University of the South Pacific and Central Queensland University. E-mail was used for teaching and learning in different ways at these institutions. At Central Queensland University, interactive e-mail was incorporated into distance education pedagogy across all courses, whereas at the University of the South Pacific email was used more informally.

Three research questions were addressed: Does cultural background affect the extent to which distance education students use e-mail to communicate with educators and other students for academic and social reasons? Does cultural background affect the academic content of e-mail messages? Does cultural background influence students' preference to ask questions or provide answers using e-mail?

Two studies were conducted in parallel. Subjects were drawn from business information systems and computer information technology taught by distance educators at the University of the South Pacific and Central Queensland
University. Four hundred University of the South Pacific students located at different regional centers were surveyed about their e-mail usage. In the Central Queensland University study, postings to course discussion lists by 867 students based in Fiji and Australia were analyzed. The results of these studies suggest that there are significant differences in the use of e-mail by distance education students from different cultural backgrounds.

High power-distance/collectivist students are more likely to use e-mail to interact socially with their peers than they are to use it for contacting their professors. These distance education students tend to ask more questions than low power-distance/individualist students, and their questions are more likely to focus on group formation or reduction of assignment ambiguity. They also tend to volunteer fewer answers than low power-distance/individualistic students. Anxiety over "loss of face" may contribute to collectivist students' reluctance to volunteer answers.

\section{FUTURE TRENDS}

Notwithstanding the geographical limitations of these studies, the findings may have wider relevance as distance education classes worldwide become more culturally diverse. Future researchers might wish to pursue a more qualitative study in different geographic settings, interviewing students and academics to gain a more indepth understanding of the reasons for some of the observed behaviors. Additional research in this area is important as we expand teaching across cultural boundaries through the use of distance education.

\section{REFERENCES}

Anakwe, U. et al. (1999). Distance learning and cultural diversity: Potential users' perspective. International Journal of Organizational Analysis, 7(3), 224-244.

Badaracco, J.L. Jr. (1991). The knowledge link. Boston: Harvard Business School Press.

Bannon, L.J. (1995). Issues in computer-supported collaborative learning. In C. O'Malley (Ed.), Computer-supported collaborative learning (pp. 267-281). Berlin: Springer-Verlag.

Davis, C.H., McMaster, J. \& Nowak, J. (2002). IT-enabled services as development drivers in low-income countries: The case of Fiji. The Electronic Journal on Information Systems in Developing Countries, 9(4), 1-18. 
Frank, J., Toland, J. \& Schenk, K. (2004). The effect of culture on email use: Implications for distance learning In C. Howard, K. Schenk \& R. Discenza (Eds.), Distance learning \& university effectiveness: Changing educational paradigms for online learning (pp. 213-233). Information Science Publishing

Freedman, K. \& Liu, M. (1996). The importance of computer experience, learning processes, and communication patterns in multicultural networking. Educational Technology Research and Development, 44(1), 43-59.

Gudykunst, W.B. (1997). Cultural variability in communication. Communication Research, 24(4), 327-348.

Guy, R.K. (1991). Distance education and the developing world: Colonisation, collaboration and control. In T.D. Evans \& B. King (Eds.), Beyond the text: Contemporary writing on distance education (pp. 152-175). Geelong, Australia: Deakin University Press.

Handel, J. (1998). Hints for teachers. Centre for the Enhancement of Teaching and Learning, University of the South Pacific.

Holden, N.J. (2002). Cross-cultural management: A knowledge management perspective. London: Prentice-Hall.

Hofstede, G. (1994). Cultures and organizations. Harper Collins.

Jarvenpaa, S.L. \& Leidner, D. (1998). Communication and trust in global virtual teams. Journal of Computer Mediated Communication, 3(4).

Jin, Z. et al. (1998). Bridging US-China cross-cultural differences using Internet and groupware technologies. Proceedings of the $7^{\text {th }}$ International Association for Management of Technology Annual Conference. Retrieved from www.cim-oem.com/bridge_8c18c.html

Jones, D. (1999). Solving some problems with university education: Part II. Proceedings of AusWeb99, the Fifth Australian World Wide Web Conference. Retrieved from ausWeb.scu.edu.au/aw99

Liang, A. \& McQueen, R.J. (1999). Computer-assisted adult interactive learning in a multi-cultural environment. Adult Learning, 11(1), 26-29.

Lockwood, F. et al. (2000, August). Review of distance and flexible learning at the University of the South Pacific. Report submitted to the Vice Chancellor and senior staff at the University of the South Pacific.

Lynch, T., Szorengi, N. \& Lodhia, S. (2002). Adoption of information technologies in Fiji: Issues in the study of cultural influences on information technology adoption.
Proceedings of the Conference on Information Technology in Regional Areas, Rockhampton, Australia.

Matthewson, C. et al. (1998). Designing the Rebbelib: Staff development in a Pacific multicultural environment. In C. Latchem \& F. Lockwood (Eds.), Staff development in open and flexible learning. London: Routledge.

Myers, M. \& Tan, F. (2002). Beyond models of national culture in information systems research. Journal of Global Information Management, 10(1), 24-32.

Olutimayin, J. (2002). Adopting modern information technology in the South Pacific: A process of development, preservation, or underdevelopment of the culture. Electronic Journal of Information Systems in Developing Countries, 9(3), 1-12.

Purcell, F. \& Toland, J. (2004). Electronic commerce for the South Pacific: A review of e-readiness. Electronic Commerce Research Journal, 4(3).

Romm, C. et al. (2001). Searching for a "killer application" for on-line teaching-or are we? Proceedings of AMCIS2001, Boston.

Warschauer, M. (1996). Comparing face-to-face and electronic discussion in the second language classroom. CALICO Journal, 13(2), 7-26.

Weick, K.E. (1979). The social psychology of organizing ( $2^{\text {nd }}$ ed.). New York: McGraw-Hill.

\section{KEY TERMS}

Container Model: Knowledge flows directly from the teacher to the learner, independently of the learner's environment.

Cultural Diversity: The way that people have different values and attitudes depending on where they were born and the society that brought them up.

Enactment: Knowledge only takes on meaning as it interacts with the learner's environment.

Individualism/Collectivism: An individualist society is one where each person is expected to be self-sufficient and look after themselves and their immediate family. A collectivist society is one where every person is a member of a group, and loyalty is to that group. Typically, in an individualist society, any money earned will be kept by the individual that earns it, whereas in a collectivist society, earnings will be shared among the group 
Long-Term Orientation: This refers to a society's attitude towards time, do they tend to plan for a long- or a short-term time horizon.

Masculinity/Femininity: Societies that are masculine would favor values such as assertiveness, competitiveness, and toughness. Societies with a more feminine focus would be more nurturing, cooperative, and concerned with the quality of life.

Migratory Knowledge: Knowledge that can travel directly from teacher to learner without changing in form or substance.

Online Group Interaction: The use of computer-mediated communication such as e-mail, chat, or a threaded discussion by a group to communicate for the purposes of carrying out a task.
Power Distance: The way authority figures are perceived: in countries with a high power distance, a leader is an authoritarian figure or a benevolent dictator and their authority will not be questioned; in a low power distance country, individuals are prepared to argue with leaders, who must be able to justify their decisions.

Social Construction: In this model of learning, knowledge, cognition, action, and communication are seen as inseparable.

Uncertainty Avoidance: This is how a society reacts to change or something that is unknown; a society with a high uncertainty avoidance will resist anything that is different. 